\title{
In Situ Reduced Multi-Core Yolk-Shell Co@C Nanospheres for Broadband Microwave Absorption
}

\author{
Mu Zhang ${ }^{1,2, *}$, Jiahang Qiu ${ }^{1,2}$, Zhen Xin ${ }^{1,2}$ and Xudong Sun ${ }^{1,2, *}$ \\ 1 Key Laboratory for Anisotropy and Texture of Materials (Ministry of Education), School of Materials Science \\ and Engineering, Northeastern University, Shenyang 110819, China; 1900581@stu.neu.edu.cn (J.Q.); \\ 2070535@stu.neu.edu.cn (Z.X.) \\ 2 Foshan Graduate School, Northeastern University, Foshan 528311, China \\ * Correspondence: zhangm@mail.neu.edu.cn (M.Z.); xdsun@mail.neu.edu.cn (X.S.)
}

Citation: Zhang, M.; Qiu, J.; Xin, Z.; Sun, X. In Situ Reduced Multi-Core Yolk-Shell Co@C Nanospheres for Broadband Microwave Absorption. Materials 2021, 14, 4610. https:// doi.org/10.3390/ma14164610

Academic Editor: George Kenanakis

Received: 23 July 2021

Accepted: 13 August 2021

Published: 17 August 2021

Publisher's Note: MDPI stays neutral with regard to jurisdictional claims in published maps and institutional affiliations.

Copyright: (c) 2021 by the authors. Licensee MDPI, Basel, Switzerland. This article is an open access article distributed under the terms and conditions of the Creative Commons Attribution (CC BY) license (https:/ / creativecommons.org/licenses/by/ $4.0 /)$.

\begin{abstract}
The preparation of yolk-shell microwave absorption materials with low density and excellent microwave absorption property requires reasonable design and economical manufacture. In this study, an efficient strategy without any templates or reducing gases has been designed to fabricate multi-core yolk-shell Co@C nanospheres by high temperature carbonization. The results showed that $\mathrm{Co}_{3} \mathrm{O}_{4}$ was completely reduced by the carbon shell to metal cobalt at temperatures above $750{ }^{\circ} \mathrm{C}$. This unique multi-core yolk-shell structure with shell of $600 \mathrm{~nm}$ and multiple cores of tens of nanometers can provide sufficient interface and space to reflect and scatter electromagnetic waves. At the same time, the metal cobalt layer and carbon layer provide magnetic loss ability and dielectric loss ability, respectively, making the composite show good wave absorption performance. The minimal RL value of samples carbonized at $750{ }^{\circ} \mathrm{C}$ reaches $-40 \mathrm{~dB}$ and the efficient absorption band reaches $9 \mathrm{GHz}$ with the thickness ranges from $2-9 \mathrm{~mm}$. Therefore, this is a facile, effective and economical strategy to prepare yolk-shell structure, which provides a new idea for the preparation of microwave absorption materials.
\end{abstract}

Keywords: multi-core yolk-shell; Co@C nanospheres; microwave absorption; high temperature carbonization

\section{Introduction}

With the rapid development of electronic devices, the microwave with a frequency in the $2 \sim 18 \mathrm{GHz}$ ranges has become a main part of electromagnetic pollution, so it is urgent to investigate the microwave absorbing materials (MAM) [1-4]. Among these materials, transition magnetic metals ( $\mathrm{Fe}, \mathrm{Co}, \mathrm{Ni}$ ) with high specific magnetism, outstanding electric conductivity and low cost has attracted a lot of attention as MAM because of its excellent magnetic loss capability endowed by natural resonance and eddy current effects [5-8]. However, in order to achieve good impedance matching, so that the electromagnetic wave can incident into the material as much as possible rather than be reflected, it is required that the impedance of the material surface should be as close as possible to the characteristic impedance of free space, that is, the values of relative complex permeability and relative complex dielectric constant should be as close as possible [9-12]. Hence, the poor impedance matching which causes an undesirable microwave absorption capacity is still a great challenge to transition metals.

In general, it is a common strategy that combines the magnetic loss materials with dielectric loss materials to form core-shell or yolk-shell composites with excellent impedance matching [13-16]. Yolk-shell structure is a special kind of core-shell structure and the structure can also be called a core@void@shell structure, which means that there is not direct contact between the core and the shell. The existence of void provides unique advantages such as low density and large surface area [17-19]. Furthermore, the outside dielectric shell $\left(\mathrm{SnO}_{2}\right.$ [20], $\mathrm{MnO}_{2}$ [21], carbon [22]) cannot only effectively protect naked magnetic 
core from oxidation, but also provide dielectric loss capacity. For instance, Liu and his coworkers [23] have fabricated yolk-shell CoNi@air@ $\mathrm{TiO}_{2}$ nanospheres with minimum RL value of $-41 \mathrm{~dB}$ and efficient absorption bandwidth (EABD) of $8 \mathrm{GHz}$ when thickness is $2.5 \mathrm{~mm}$, which have both strong magnetic loss and dielectric loss capacity. Wang et al. [24] synthesized MOF derived multi-interfacial Ni@C@ZnO composites as outstanding MAM with minimum RL value of $-55.8 \mathrm{~dB}$ and EABD of $4.1 \mathrm{GHz}$ when thickness is $2.5 \mathrm{~mm}$. The ordinary design strategies to form yolk-shell structures use $\mathrm{SiO}_{2}$ as a template. Typically, a layer of $\mathrm{SiO}_{2}$ was grown on the core using the stöber method, and then the required shell was grown on the $\mathrm{SiO}_{2}$ layer. Finally, an alkali solution or hydrofluoric acid was used to remove $\mathrm{SiO}_{2}$ to form a void, and the yolk-shell structure was prepared. Nevertheless, the ordinary design strategies with $\mathrm{SiO}_{2}$ as a template to form a yolk-shell structure are often too complicated and wasteful. At the same time, the alkaline solution or hydrofluoric acid solution used to etch $\mathrm{SiO}_{2}$ layer has certain risks and may react with other core or shell materials, These factors all restrict the development of template method [25-28].

To address these issues, many strategies to form yolk-shell structures without a template have been developed, such as one-pot [29,30], Ostwald ripening [31], MOF [32,33], Kirkendall effect [34,35] and so on [36,37]. For example, Qin et al. [38] synthesized multishelled hollow $\mathrm{NiCo}_{2} \mathrm{O}_{4}$ spheres using one-pot and the minimum Reflection Loss (RL) reached $-36.3 \mathrm{~dB}$ at $13.16 \mathrm{GHz}$ while the matching thickness is $1.86 \mathrm{~mm}$. Zhao and his groups [39] fabricated yolk-shell $\mathrm{Ni@void@SnO} \mathrm{S}_{2}$ microspheres via the Kirkendall effect and the composites have a minimum RL value of $-45.5 \mathrm{~dB}$ and EABD of $8.2 \mathrm{GHz}$ when thickness is $2.0 \mathrm{~mm}$. Shi et al. [40] designed $\mathrm{Fe} @ \mathrm{SiO}_{2} @ \mathrm{C}-\mathrm{Ni}$ yolk-shell nanospheres in the reduction of high temperature hydrogen gas and the triple-shelled architecture composed of magnetic loss materials and dielectric loss materials endows it with a broad efficient absorption band reaching $8.2 \mathrm{GHz}$ with a thickness of only $2 \mathrm{~mm}$. So far, these template-free methods for preparing yolk-shell structures have achieved the purpose of simple and economical process to some extent, but they still have disadvantages such as uncontrollable size, environmental harm and certain risks, which restrict the further development of the yolk-shell structure [41-43].

Herein, considering that the preparation of $\mathrm{Co}_{3} \mathrm{O}_{4}$ and carbon shell is simple and controllable, and carbon can reduce $\mathrm{Co}_{3} \mathrm{O}_{4}$ to metal cobalt at low temperature without by-products a facile strategy was proposed for preparing certain sized yolk-shell Co@C nanospheres without employing templates or dangerous reducing gases. By increasing the temperature of heat treatment, the inner $\mathrm{Co}_{3} \mathrm{O}_{4}$ core was reduced by the carbon shell which is prepared from the carbonization of the outer phenolic resin, and the special structure of the multi-core yolk-shell Co@C nanospheres was obtained. Due to the synergistic effect of the magnetic loss capacity of the multi-cobalt core and the dielectric loss capacity of the outer carbon layer, as well as the multi-scattering attenuation effect of the hollow structure on the electromagnetic wave, the composites exhibit a good microwave absorbing performance. The minimal RL value reaches $-40 \mathrm{~dB}$ and the EABD reaches $9 \mathrm{GHz}$ with the thickness range of 2-9 mm. This facile method might provide help for the development of high performance MAM.

\section{Materials and Methods}

\subsection{Materials}

All reagents applied in this experiment were analytical grade. Cobaltous nitrate hexahydrate $\left(\mathrm{Co}\left(\mathrm{NO}_{3}\right)_{3} \cdot 6 \mathrm{H}_{2} \mathrm{O}\right)$, isopropanol $\left(\mathrm{C}_{3} \mathrm{H}_{8} \mathrm{O}\right)$, glycerol $\left(\mathrm{C}_{3} \mathrm{H}_{8} \mathrm{O}_{3}\right)$, formaldehyde $(37 \%)$, resorcinol, ammonia solution $\left(\mathrm{NH}_{3} \mathrm{OH}, 26 \%\right)$, and ethanol were purchased from Sinopharm Chemical Reagent, Co. Ltd. (Shenyang, Liaoning, China). Deionized water used in all experiments was obtained from a Milli-Q system (Millipore, Bedford, MA, USA).

\subsection{Synthesis of $\mathrm{Co}_{3} \mathrm{O}_{4}$ Nanospheres}

$\mathrm{Co}_{3} \mathrm{O}_{4}$ nanospheres were obtained using the method reported by previous literature [44]. In short, $0.272 \mathrm{~g}$ of $\left(\mathrm{Co}\left(\mathrm{NO}_{3}\right)_{3} \cdot 6 \mathrm{H}_{2} \mathrm{O}\right)$ and $10 \mathrm{~mL}$ glycerol were dissolved into 
$50 \mathrm{~mL}$ isopropanol to form a homogeneous pink solution under constant stirring. Subsequently, the solution was transferred into a Teflon-lined stainless steel autoclave and kept at $180^{\circ} \mathrm{C}$ for $2 \mathrm{~h}$. After cooling to room temperature, the precipitate was collected by centrifugation, washed by deionized water and ethanol several times and then dried at $60{ }^{\circ} \mathrm{C}$ for $12 \mathrm{~h}$. The well-dried precursor was then calcined at $350{ }^{\circ} \mathrm{C}$ in air for $2 \mathrm{~h}$ with a heating rate of $2{ }^{\circ} \mathrm{C} / \mathrm{min}$ to obtain $\mathrm{Co}_{3} \mathrm{O}_{4}$ nanospheres.

\subsection{Synthesis of Co@C Nanospheres}

The yolk-shell Co@C nanospheres were prepared by a typical in situ polymerization and high-temperature carbonization method [45,46]. Briefly, $0.3 \mathrm{~g}$ of synthesized $\mathrm{Co}_{3} \mathrm{O}_{4}$ nanospheres were dispersed in a mixed solution which contains $80 \mathrm{~mL}$ of water, $32 \mathrm{~mL}$ of ethanol, and $0.4 \mathrm{~mL}$ of ammonia. Then, the mixed solution was treated with ultrasonication for $30 \mathrm{~min}$ to form a homogeneous suspension. The mixture was then mechanically stirred for $30 \mathrm{~min}$ before adding $0.20 \mathrm{~g}$ of resorcinol. After resorcinol was completely dissolved, $0.28 \mathrm{~mL}$ of formaldehyde solution ( $37 \mathrm{wt} . \%$ ) was introduced into the suspension with continuous stirring for $24 \mathrm{~h}$. The suspending $\mathrm{Co}_{3} \mathrm{O}_{4} @$ phenolic resin $\left(\mathrm{Co}_{3} \mathrm{O}_{4} @ P R\right)$ nanospheres were separated by centrifugation, and washed by deionized water and ethanol 3 times, respectively. Then, the composites were dried at $60{ }^{\circ} \mathrm{C}$ for $12 \mathrm{~h}$. Finally, the $\mathrm{Co}_{3} \mathrm{O}_{4} @ \mathrm{PR}$ nanospheres were carbonized and reduced in a tubular furnace under the atmosphere of argon for $1 \mathrm{~h}$ at a heating rate of $5^{\circ} \mathrm{C} / \mathrm{min}$. The samples were marked as $\mathrm{S} 1, \mathrm{~S} 2, \mathrm{~S} 3$, samples of which were treated under different temperature of $650{ }^{\circ} \mathrm{C}, 750{ }^{\circ} \mathrm{C}$, $850^{\circ} \mathrm{C}$, respectively.

\subsection{Characterization}

The Crystalline structures and phase composition of obtained products were characterized by X-ray diffraction (XRD, smartlab9) with a Cu K $\alpha$ source (40 KV, $200 \mathrm{~mA})$. The morphology and size were obtained by scanning electron microscopy (SEM, JSM$7001 \mathrm{~F}$ ) with an accelerating voltage of $20 \mathrm{kV}$. The transmission electron microscopy (TEM) images were characterized on JEM-2100F with an accelerating voltage of $200 \mathrm{kV}$. The magnetic hysteresis loops were measured by vibrating sample magnetometer (VSM, Lake Shore Cryotronics, Westerville, OH, USA) at room temperature. The X-ray photoelectron spectrometer (XPS, Axis Supra) was measured on an Axis Supra with an Al K $\alpha$ X-ray source. The relative complex permeability and relative permittivity of the sample in the frequency range of $2-18 \mathrm{GHz}$ were characterized by a vector network analyzer (VNA, Agilent N5234A). After mixing the products with the paraffin in the ratio of 3:7 uniformly, the annular sample with outer diameter of $7 \mathrm{~mm}$ and inner diameter of $3 \mathrm{~mm}$ was pressed, and the thickness was about $2.00 \mathrm{~mm}$.

\section{Results and Discussion}

The synthesis process of yolk-shell Co@C nanospheres is schematically illustrated in Figure 1. Co-glycerate nanospheres are formed by solvothermal action of $\mathrm{Co}^{3+}$ and glycerol, and are then calcined in air to form $\mathrm{Co}_{3} \mathrm{O}_{4}$. Then, resorcinol and formaldehyde formed a phenolic resin layer on the surface of $\mathrm{Co}_{3} \mathrm{O}_{4}$ by in situ polymerization. Finally, the microspheres were carbonized and reduced in protective gas at high temperature to form a multi-core yolk-shell Co@C structure.

XRD patterns of $\mathrm{Co}_{3} \mathrm{O}_{4}, \mathrm{~S} 1, \mathrm{~S} 2$ and $\mathrm{S} 3$ are shown in Figure 2. $\mathrm{Co}_{3} \mathrm{O}_{4}$ nanospheres' diffraction peaks can well match the spinel phase of $\mathrm{Co}_{3} \mathrm{O}_{4}$ (JCPDS 73-1701), indicating that the precursor transformed into the $\mathrm{Co}_{3} \mathrm{O}_{4}$ phase after being calcined. The same diffraction peaks at $44^{\circ}, 51^{\circ}, 76^{\circ}$ in all of the samples can be in good agreement with (111), (200), and (220) planes of fcc metallic cobalt (JCPDS 89-7093), and the remaining diffraction peaks of S1 are matched with that of CoO (JCPDS 43-1004), which indicates that the calcination temperature of $650{ }^{\circ} \mathrm{C}$ is not enough to help the carbon layer completely reduce $\mathrm{Co}_{3} \mathrm{O}_{4}$ to zero-valent metallic cobalt. At the same time, although the formed metal cobalt can 
catalyze the transition from amorphous carbon layer to graphite, the diffraction peak of graphite carbon does not appear in the XRD patterns [47,48].

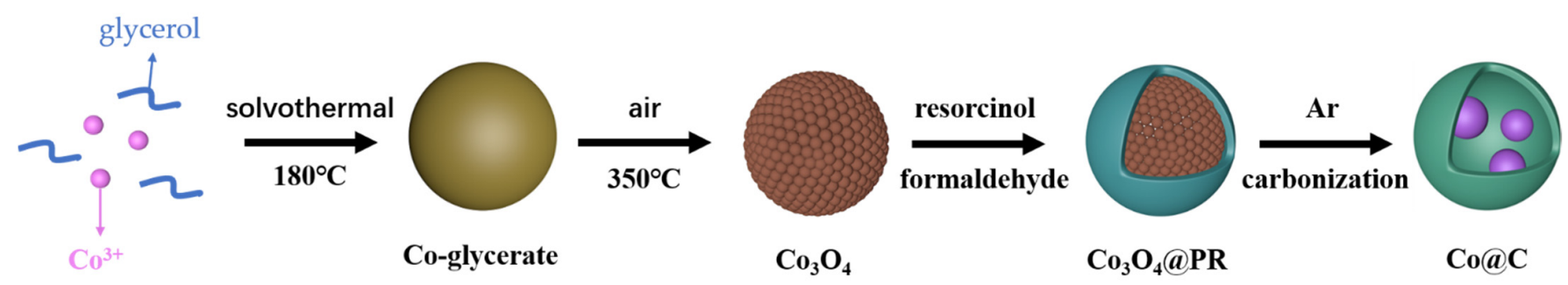

Figure 1. Schematic illustration of the synthetic strategy for multi-core yolk-shell Co@C nanospheres.

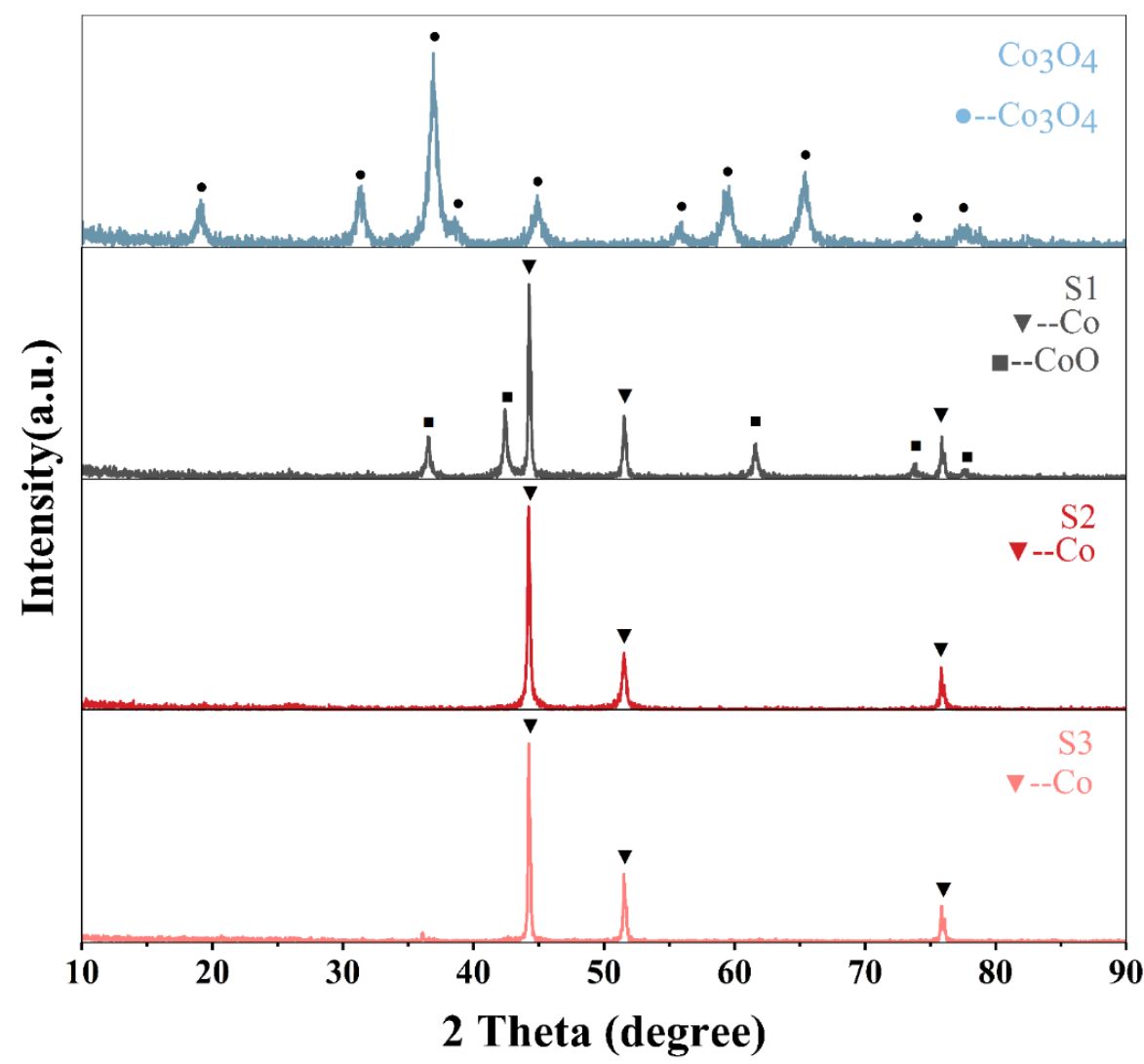

Figure 2. The XRD patterns of $\mathrm{Co}_{3} \mathrm{O}_{4}, \mathrm{~S} 1, \mathrm{~S} 2, \mathrm{~S} 3$.

Figure 3 illustrates the morphology evolution of $\mathrm{Co}_{3} \mathrm{O}_{4}$ to yolk-shell Co@C nanospheres at different calcination temperatures. $\mathrm{Co}_{3} \mathrm{O}_{4}$ nanospheres are initially synthesized with an average size of $700 \mathrm{~nm}$ (Figure 3a). After in situ polymerization and calcination at $650{ }^{\circ} \mathrm{C}$ for $1 \mathrm{~h}$, the shape of the nanoparticles is distorted and the internal particles shrink to form several nanospheres of different sizes. Combined with the XRD patterns, it is found that the inner spheres of the carbon layer are composed of metal cobalt and $\mathrm{CoO}$. Compared with the sample calcinated at $650{ }^{\circ} \mathrm{C}$, the outer carbon layer is preserved better in spherical shape at 750 and $850{ }^{\circ} \mathrm{C}$, and the inner cobalt oxide is completely reduced to several irregular metal cobalt particles with similar size (Figure 3c,d). The morphology and structure of the $\mathrm{S} 2$ is further characterized by TEM. As can be clearly seen from the image, there are many small particles of tens of nanometers evenly distributed in the inner space wrapped by the carbon layer (Figure 3e). HRTEM images show that the lattice fringes of the internal small particle can match well with the (111) crystal plane of metal cobalt, further proving that cobalt particles are formed after in situ reduction of $\mathrm{Co}_{3} \mathrm{O}_{4}$ in the carbon shell (Figure 3f). 

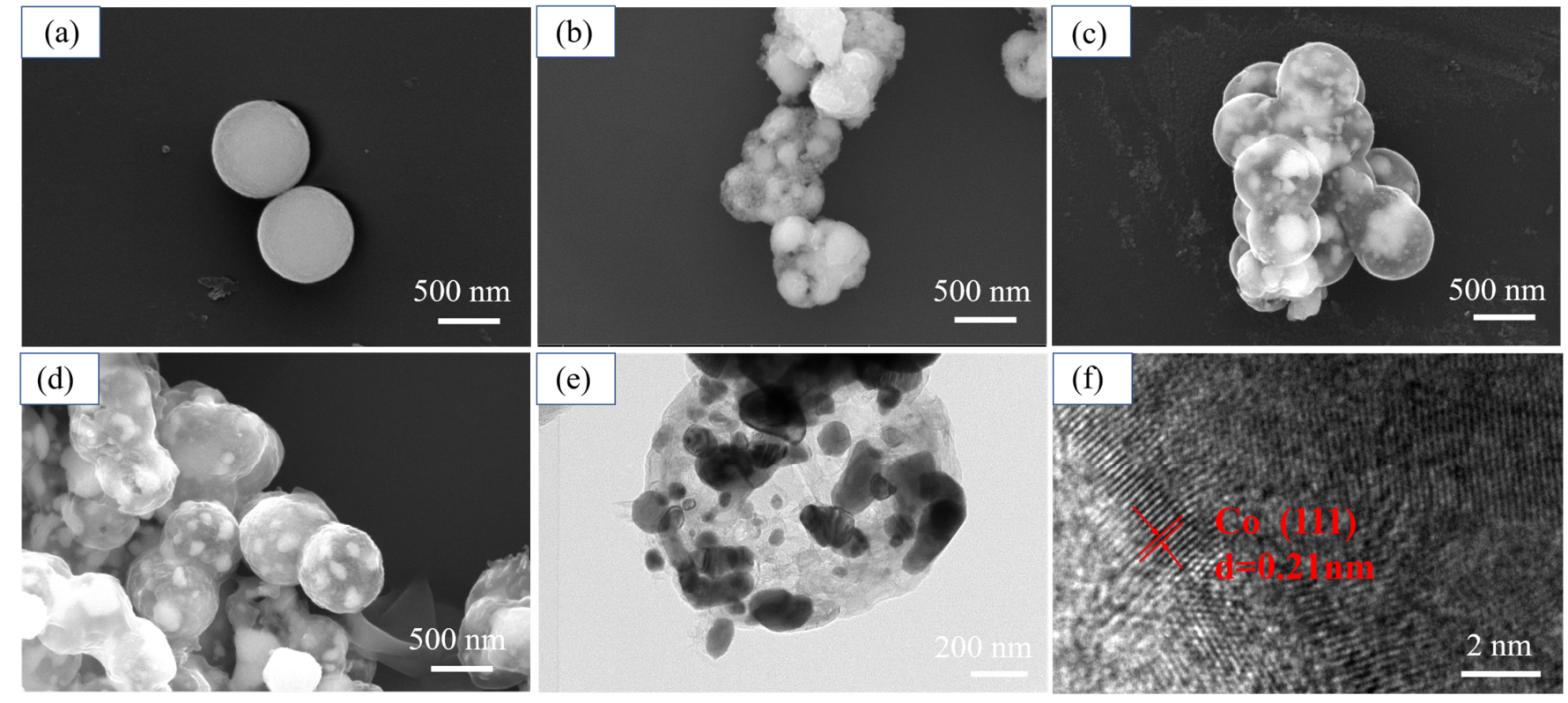

Figure 3. FE-SEM images of (a) $\mathrm{Co}_{3} \mathrm{O}_{4}$, (b) $\mathrm{S} 1$, (c) S2, (d) S3. TEM image of (e) S2. (f) HRTEM image of Co wrapped in carbon shell of S2.

The magnetization properties of all the samples are characterized by VSM with a magnetic field of $-10,000$ Oe-10,000 Oe at room temperature. Figure 4a illustrates the magnetic hysteresis loops of S1, S2 and S3. The saturation magnetization $\left(\mathrm{M}_{\mathrm{s}}\right)$ of $\mathrm{S} 1, \mathrm{~S} 2$, S3 are $67.7,81.0,107.2 \mathrm{emu} / \mathrm{g}$, respectively. It can be found that the $\mathrm{M}_{\mathrm{s}}$ of the sample increases with the increase in the reduction temperature. The increase in $\mathrm{M}_{\mathrm{S}}$ from S1 to $\mathrm{S} 2 \mathrm{can}$ be attributed to the enhancement of magnetism caused by the reduction of more antiferromagnet $\mathrm{Co}_{3} \mathrm{O}_{4}$ to ferromagnetic cobalt metal, while the increase in $\mathrm{M}_{\mathrm{S}}$ from S2 to S3 may be due to the increase in the crystallinity of cobalt metal with the increase in reduction temperature. The coercivity $\left(\mathrm{H}_{\mathrm{c}}\right)$ values of $\mathrm{S} 1, \mathrm{~S} 2, \mathrm{~S} 3$ are $98.1,210.3,90.9$ Oe, respectively. For ferromagnetic MAM, initial permeability $\left(\mu_{\mathrm{i}}\right)$ can be expressed by the following formula [24,49]:

$$
\mu_{\mathrm{i}}=\frac{\mathrm{M}_{\mathrm{s}}^{2}}{\mathrm{akH}_{\mathrm{c}} \mathrm{M}_{\mathrm{s}}+\mathrm{b} \lambda \xi}
$$

where $\mathrm{a}$ and $\mathrm{b}$ are two constants determined by the material composition, $\mathrm{k}$ is the magnetostriction constant, $\lambda$ is the magnetostriction constant, and $\xi$ is an elastic strain parameter of the crystal. An increase in $\mu_{\mathrm{i}}$ usually means an increase in magnetic loss capacity, and both high $\mathrm{M}_{\mathrm{S}}$ and low $\mathrm{H}_{\mathrm{c}}$ are beneficial to the increase in $\mu_{\mathrm{i}}$.

In order to further elucidate the surface element composition and atomic configuration of S2, X-ray photoelectron spectroscopy (XPS) was characterized in Figure 4b-d. As can be seen from Figure $4 \mathrm{~b}$, the survey spectrum of $S 2$ contains $C 1 \mathrm{~s}, \mathrm{Co} 2 \mathrm{p}$ and $\mathrm{O} 1 \mathrm{~s}$. Figure 2 exhibits high resolution Co $2 \mathrm{p}$ spectrum, where the peaks at $781.9 \mathrm{eV}$ and $797.6 \mathrm{eV}$ are attributed to $\mathrm{Co}^{2+} 2 \mathrm{p}_{3 / 2}$ and $\mathrm{Co}^{2+} 2 \mathrm{p}_{1 / 2}$ spectrums, respectively [50,51]. Two peaks at $785.5 \mathrm{eV}$ and $803.6 \mathrm{eV}$ are the satellite peaks that accompany the two peaks of $\mathrm{Co}^{2+}$. The peak located at $795.0 \mathrm{eV}$ can be assigned to $\mathrm{Co}^{0}$. Combined with the XRD spectrum of S2, it can be inferred that the peaks of $\mathrm{Co}^{2+}$ are due to the oxidation of surface of sample. The C 1s peaks at $284.8,285.7,287.4,288.4,289.5 \mathrm{eV}$ are assigned to aromatic ring structure, phenolic hydroxyl group, C-O linkage, carbonyl groups, carbonyl groups, respectively (Figure 4d). It is noteworthy that there is a peak that can be assigned to $\mathrm{O} 1 \mathrm{~s}$ in the survey spectrum. According to the $\mathrm{XRD}$ result of $\mathrm{S} 2, \mathrm{Co}_{3} \mathrm{O}_{4}$ was completely reduced to metal cobalt, so it was speculated that the occurrence of the $\mathrm{O} 1 \mathrm{~s}$ peak might be due to the incomplete carbonization of phenolic resin and the oxidation of the surface of metal cobalt. 
(a)

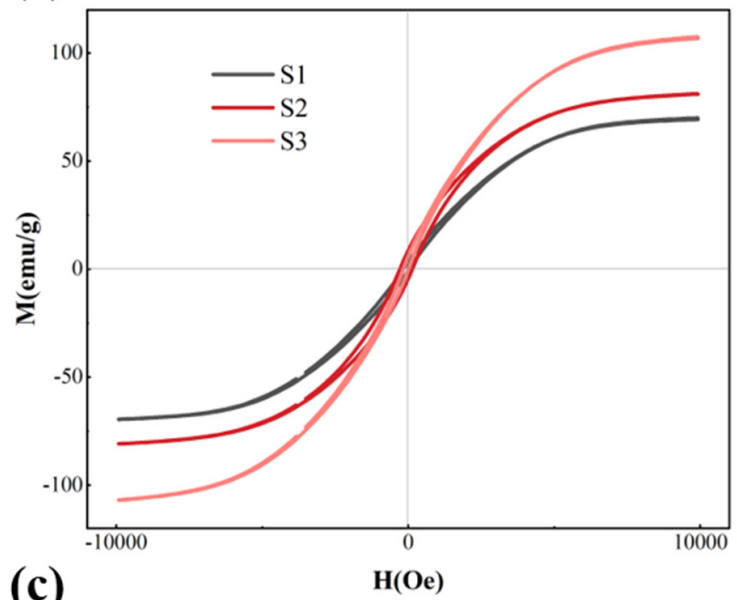

(c)

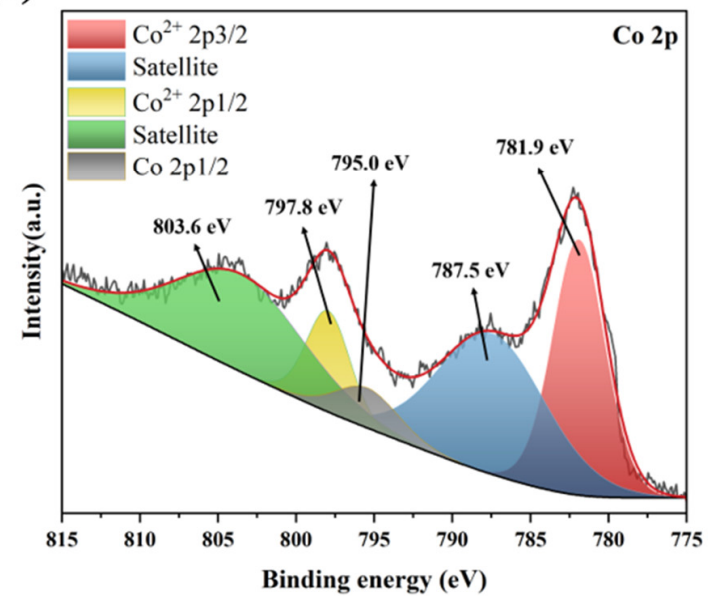

(b)
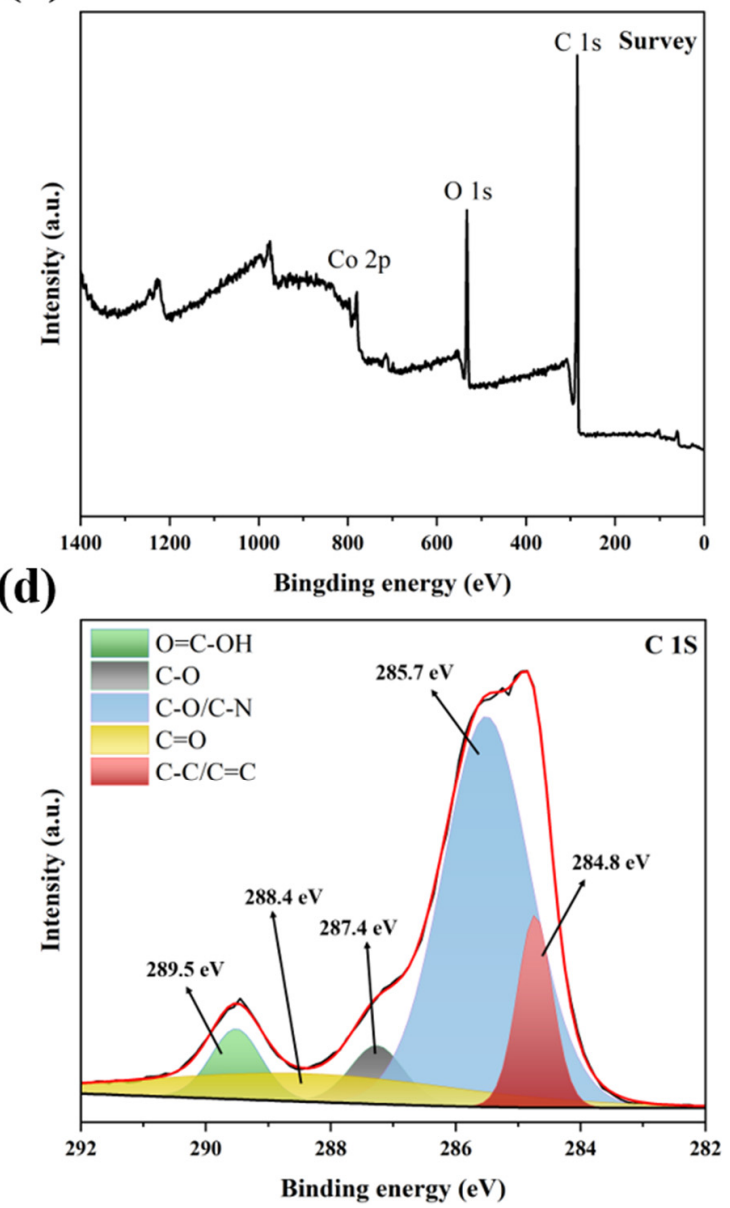

Figure 4. (a) Magnetic hysteresis loops of S1, S2 and S3, (b) XPS survey spectrum of S2, (c) high resolution Co 2p regions of $\mathrm{S} 2$, (d) high resolution C 1s regions of S2.

Complex permittivity $\left(\varepsilon_{\mathrm{r}}=\varepsilon^{\prime}-\mathrm{j} \varepsilon^{\prime \prime}\right)$ and complex permeability $\left(\mu_{\mathrm{r}}=\mu^{\prime}-\mathrm{j} \mu^{\prime \prime}\right)$ of the MAM are measured by the vector network analyzer, which determines the absorbing performance of the MAM at the GHz frequency band (Figure 5a-f). The real parts of complex permittivity $\left(\varepsilon^{\prime}\right)$ and complex permeability $\left(\mu^{\prime}\right)$ decide the storage capacity of electromagnetic energy, while the imaginary parts of complex permittivity $\left(\varepsilon^{\prime \prime}\right)$ and complex permeability $\left(\mu^{\prime \prime}\right)$ represent the loss capacity of electromagnetic energy. Figure 5a shows the $\varepsilon^{\prime}$ of all samples in the range of $2-18 \mathrm{GHz}$; it can be found that the $\varepsilon^{\prime}$ of $\mathrm{Co}_{3} \mathrm{O}_{4}$ and S1 are both around 2.5, and there is no change with the increase in frequency. The $\varepsilon^{\prime}$ of $\mathrm{S} 2$ and S3 are relatively high and fluctuate around 6 as the frequency changes. Similarly, the $\varepsilon^{\prime \prime}$ values of $\mathrm{Co}_{3} \mathrm{O}_{4}$ and $\mathrm{S} 1$ fluctuate around 0 with frequency changes, while the $\varepsilon^{\prime \prime}$ values of S2 and S3 fluctuate around 1 with frequency increasing, with a peak value of around 3.5 at 17.5 GHz (Figure $5 b$ ). According to the free electron theory, $\varepsilon^{\prime \prime} \approx 1 / 2 \pi \rho f \varepsilon_{0}$ [52,53], where $\rho$ stands for resistivity. It can be found that high conductivity can lead to the increase in $\varepsilon^{\prime \prime}$. Therefore, the increase in $\varepsilon^{\prime \prime}$ value of S2 and S3 may be due to the increase in conductivity caused by the increase in metal cobalt content and the deepening of graphitization degree of carbon layer. Dielectric tangent loss factors $\left(\tan \delta_{\varepsilon}=\varepsilon^{\prime \prime} / \varepsilon^{\prime}\right)$ represents the dielectric loss capacity of a MAM. The $\tan \delta_{\varepsilon}$ of S2 and S3 varies around 0.2 and reaches the peak value of 0.7 at $17.5 \mathrm{GHz}$, while the values of $\mathrm{Co}_{3} \mathrm{O}_{4}$ and $\mathrm{S} 1$ stay at about 0 with the change in frequency, which proves that the dielectric loss capacity of $\mathrm{S} 2$ and $\mathrm{S} 3$ is stronger than that of $\mathrm{Co}_{3} \mathrm{O}_{4}$ and $\mathrm{S1}$ in the frequency range of $2-18 \mathrm{GHz}$ (Figure $5 \mathrm{c}$ ). In terms of complex permeability, the values of both the real part and the imaginary part of the four samples are very close. The real part stays at about 1 with the increase in frequency, while the 
imaginary part stays at about 0 (Figure $5 \mathrm{~d}$,e). Similarly, the magnetic loss tangent factors $\left(\tan \delta \mu=\mu^{\prime \prime} / \mu^{\prime}\right)$ of the four samples are also very close, and stay at about 0 with the change in frequency, which proves that the four samples only have very weak magnetic loss ability close to each other, and the increase in saturation magnetization does not bring substantial enhancement of magnetic loss ability (Figure 5f).

(a)
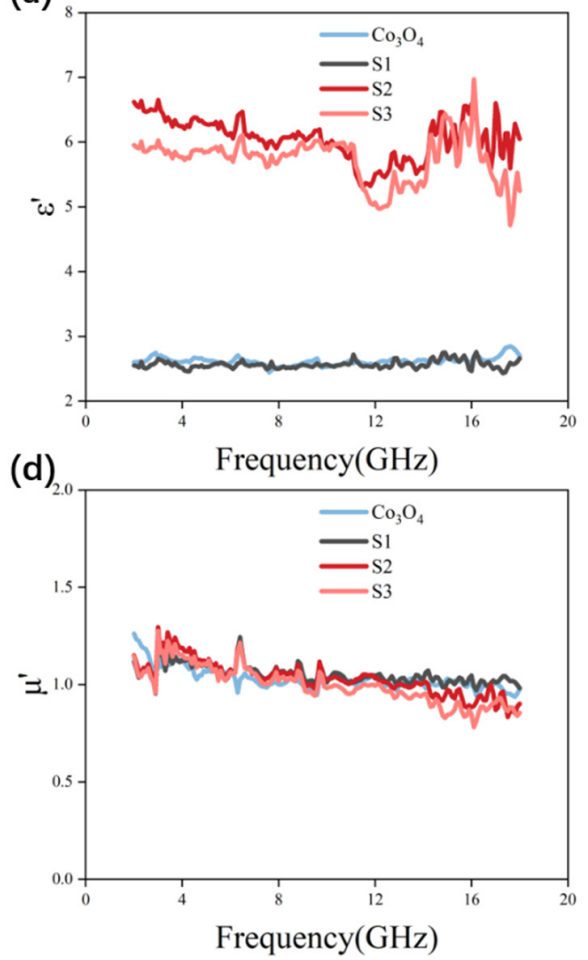

(b)

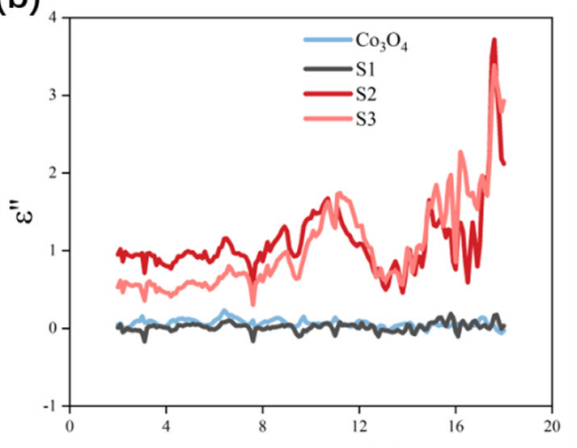

(e)

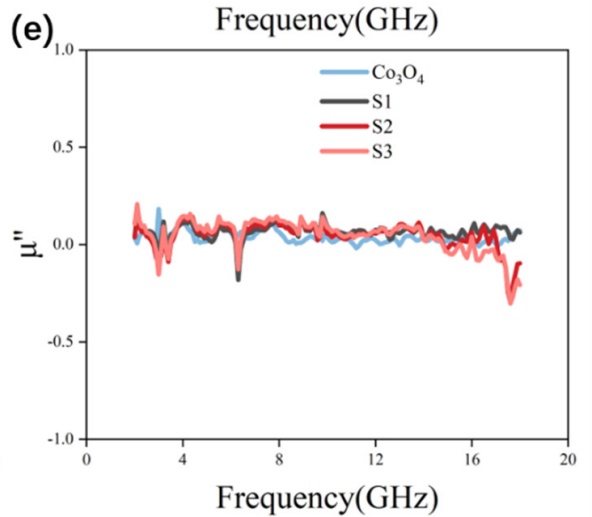

(c)

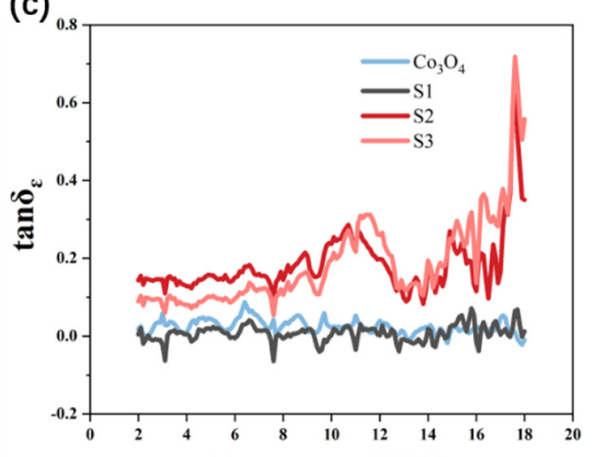

(f)

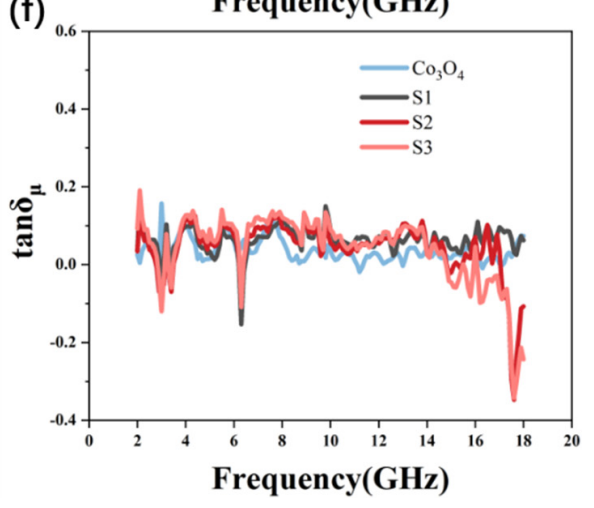

Figure 5. Electromagnetic parameters of $\mathrm{Co}_{3} \mathrm{O}_{4} \mathrm{~S} 1 \mathrm{~S} 2, \mathrm{~S} 3$ : (a) $\varepsilon^{\prime}$, (b) $\varepsilon^{\prime \prime}$, (c) dielectric tangent loss factor $\tan \delta \varepsilon,(\mathbf{d}) \mu^{\prime},(\mathbf{e}) \mu^{\prime \prime}$, (f) magnetic loss tangent factor $\tan \delta_{\mu}$.

For magnetic microwave absorbing materials, the mechanisms of magnetic loss mainly include natural resonance, eddy current loss, hysteresis loss and domain wall resonance $[54,55]$. The hysteresis loss can be ignored in the case of a weak electromagnetic field, while the domain wall resonance has a good response behavior, mainly in the $\mathrm{MHz}$ frequency band. Therefore, the main mechanisms in the $\mathrm{GHz}$ frequency band are natural resonance and eddy current loss. The eddy current loss can be expressed by the following formula [56]:

$$
\mu^{\prime \prime}=2 \pi \mu_{0}\left(\mu^{\prime}\right)^{2} \sigma \cdot d^{2} f / 3
$$

where $\sigma$ is the electrical conductivity and $\mu_{0}$ is the permeability in vacuum. The formula can be converted to $C_{0}=\mu\left(\mu^{\prime}\right)^{-2} \mathrm{f}^{-1}$, which means that $C_{0}$ will remain constant if the magnetic loss of the material is caused solely by eddy current loss. Figure 6a shows the curve of $C_{0}$ of the samples changing with frequency in the range of 2-18 GHz. When the frequency is in the range of $6-18 \mathrm{GHz}$, the $\mathrm{C}_{0}$ values of the four samples remain around 0 as the frequency changes, which proves that the magnetic loss of the four samples in this frequency band is completely caused by the eddy current loss. Meanwhile, according to the previous report, natural resonance generally occurs in the frequency band below $6 \mathrm{GHz}$. As shown in Figure 6a, there are certain resonance peaks in the $\mathrm{C}_{0}$ values of the four samples in the frequency band between 2-6 GHz. Therefore, it can be speculated that these resonance peaks are caused by natural resonance. 
(a)

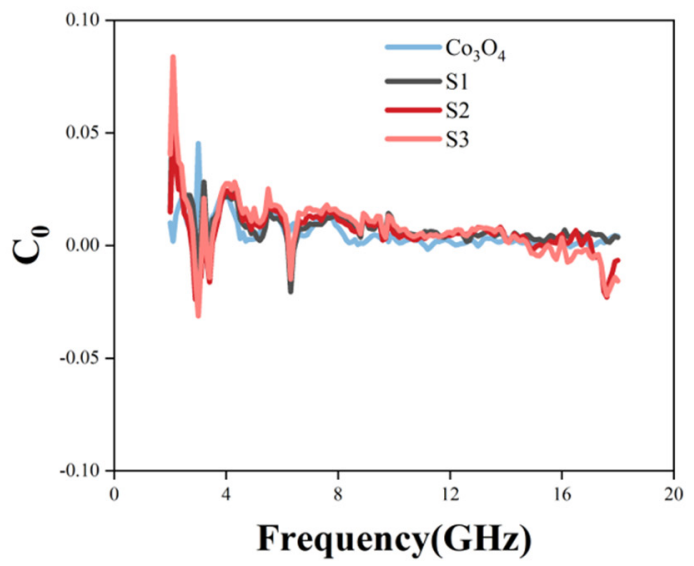

(b)

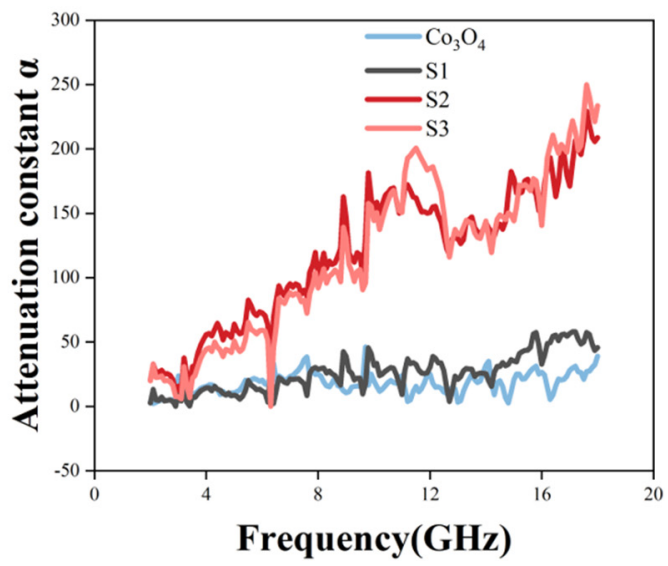

Figure 6. Electromagnetic parameters: (a) $C_{0}$ value (b) attenuation constant $\alpha$.

According to the transmission line theory, the attenuation constant $\alpha$ determines the ability of the MAM to attenuate the incident electromagnetic waves, which can be defined as [57]:

$$
\alpha=\left(\frac{\sqrt{2} \pi \mathrm{f}}{\mathrm{c}}\right) \sqrt{\mu_{\mathrm{r}}^{\prime \prime} \varepsilon_{\mathrm{r}}^{\prime \prime}-\mu_{\mathrm{r}}^{\prime} \varepsilon_{\mathrm{r}}^{\prime}}+\sqrt{\left(\mu_{\mathrm{r}}^{\prime \prime} \varepsilon_{\mathrm{r}}^{\prime \prime}-\mu_{\mathrm{r}}^{\prime} \varepsilon_{\mathrm{r}}^{\prime}\right)^{2}+\left(\mu_{\mathrm{r}}^{\prime \prime} \varepsilon_{\mathrm{r}}^{\prime}-\mu_{\mathrm{r}}^{\prime} \varepsilon_{\mathrm{r}}^{\prime \prime}\right)^{2}}
$$

where $\mathrm{f}$ is the frequency of microwave and $\mathrm{c}$ is the velocity of electromagnetic wave in vacuum. As demonstrated in Figure $6 b$, the $\alpha$ values of the four samples have different increasing trends with the increase in frequency. Among them, the $\alpha$ values of S2 and S3 have a more obvious increasing trend, which can reach 240 at $18 \mathrm{GHz}$, while the $\alpha$ values of $\mathrm{Co}_{3} \mathrm{O}_{4}$ and $\mathrm{S} 1$ can only reach 25 at $18 \mathrm{GHz}$. Obviously, in the frequency band of $2-18 \mathrm{GHz}$, the ability of samples S2 and S3 to attenuate electromagnetic waves is much higher than that of $\mathrm{Co}_{3} \mathrm{O}_{4}$ and S1. Such a result is consistent with the results of dielectric loss factor and magnetic loss factor in Figure 5.

Based on the complex permittivity and complex permeability of MAM, the reflection loss (RL) can be calculated by the transmission line theory. The calculation method is shown as follows [58,59]:

$$
R L(d B)=20 \log \left|\frac{Z_{\text {in }}-1}{Z_{\text {in }}+1}\right|
$$

where $Z_{\text {in }}$ represents the input impedance of the material, and the calculation formula is as follows:

$$
Z_{\text {in }}=\sqrt{\frac{\mu_{\mathrm{r}}}{\varepsilon_{\mathrm{r}}}} \tanh \left[\mathrm{j}\left(\frac{2 \pi}{\mathrm{c}}\right) \mathrm{fd} \sqrt{\mu_{\mathrm{r}} \varepsilon_{\mathrm{r}}}\right]
$$

where $\mathrm{c}$ represents the speed of light in free space, $\mathrm{f}$ represents the frequency of electromagnetic waves, and d represents the thickness of the absorber. Figure 6 shows the three-dimensional diagrams and contour diagrams of the RL values of $\mathrm{Co}_{3} \mathrm{O}_{4}, \mathrm{~S} 1, \mathrm{~S} 2$ and $\mathrm{S} 3$ in the frequency range of $2-18 \mathrm{GHz}$ and $\mathrm{d}$ in the range of $1-9 \mathrm{~mm}$. It can be seen from the figure that $\mathrm{Co}_{3} \mathrm{O}_{4}$ and $\mathrm{S} 1$ do not show distinct microwave absorption performance (Figure 7a-d). When the range of the thickness of the absorber is 1-9 $\mathrm{mm}$ and the range of frequency of microwave is $2-18 \mathrm{GHz}$, no RL values reach effective value of $-10 \mathrm{~dB}$ (absorbing $90 \%$ electromagnetic waves). The minimum $\mathrm{RL}$ value of $\mathrm{Co}_{3} \mathrm{O}_{4}$ is $-4.4 \mathrm{~dB}$ when $\mathrm{d}$ is $7.6 \mathrm{~mm}$ and $\mathrm{f}$ is $18 \mathrm{GHz}$ and, the minimum RL value of $\mathrm{S} 1$ is $-7.4 \mathrm{~dB}$ when $\mathrm{d}$ is $8.9 \mathrm{~mm}$ and $\mathrm{f}$ is $15.8 \mathrm{GHz}$. The performance of such weak absorbing properties is consistent with their poor values of dielectric and magnetic loss factors. In contrast, S2 and S3 both have good wave absorption performance. When the $\mathrm{d}$ of S2 is $7.4 \mathrm{~mm}$, the minimum RL value reaches $-40 \mathrm{~dB}($ at $13 \mathrm{GHz}$ ) and the $\mathrm{EAB}$ also reaches $2 \mathrm{GHz}$ (from 11.9 GHZ to $13.9 \mathrm{GHz}$ ), while when the $\mathrm{d}$ of $\mathrm{S} 3$ is $7.9 \mathrm{~mm}$, the minimum RL value is $-36 \mathrm{~dB}$ and the $\mathrm{EAB}$ is $2.2 \mathrm{GHz}$ (from $11.5 \mathrm{GHz}$ to $13.7 \mathrm{GHz}$ ). In general, materials with high 
microwave absorption performance are requested to possess low absorber thickness, low density, wide efficient absorption bandwidth and strong absorption ability. According to Figure 8, compared with other reported yolk-shell structure composites, yolk-shell Co@C nanospheres have good absorption ability and efficient absorption bandwidth, but they need a high absorber thickness, which limits their practical application ability. However, considering the development potential of low-density yolk-shell materials in the field of microwave absorption materials, this simple and controllable method of in situ reduction can be extended to other metal materials to prepare the yolk-shell materials with better microwave absorption properties.

(a)

(c)
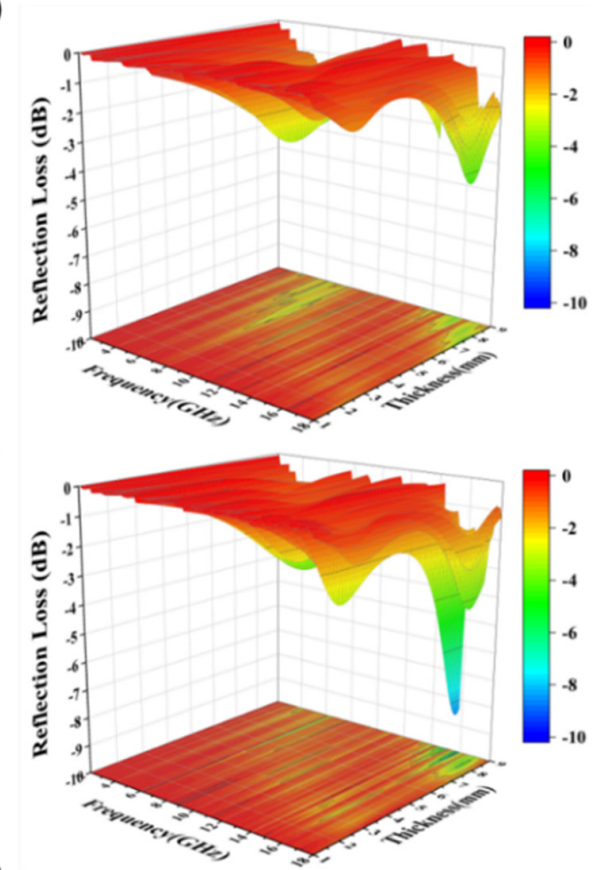

(e)

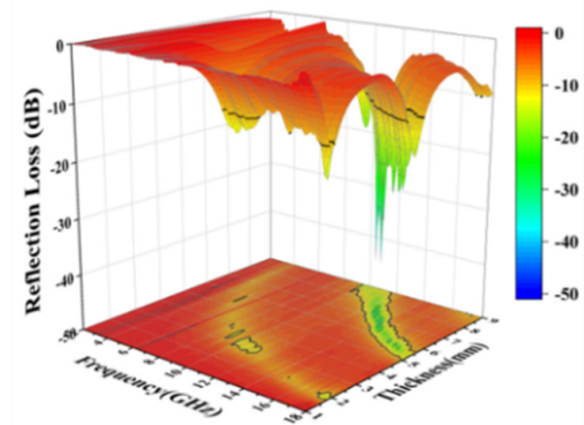

(g)

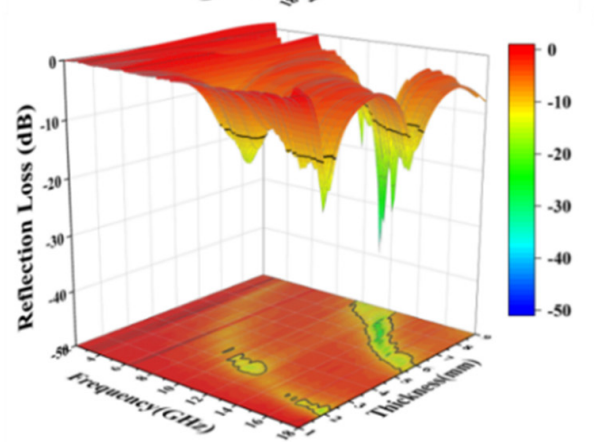

(b)

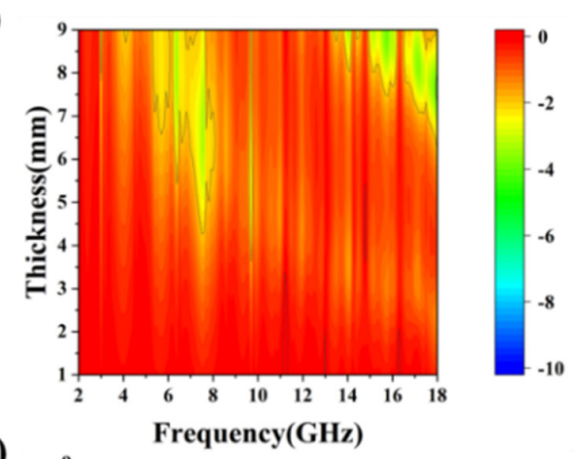

(d)

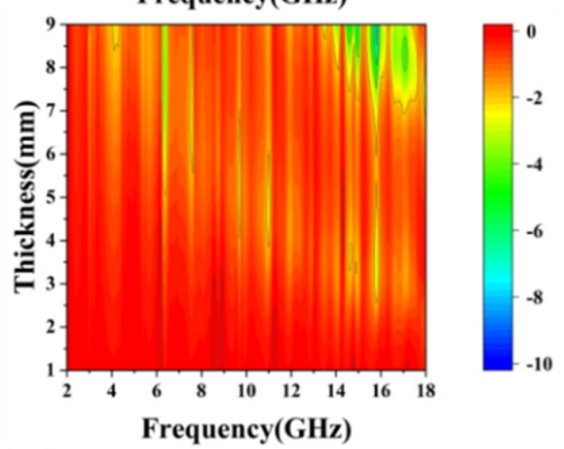

(f)

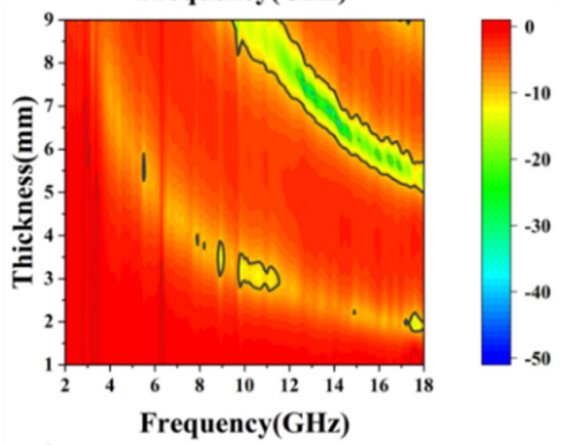

(h)

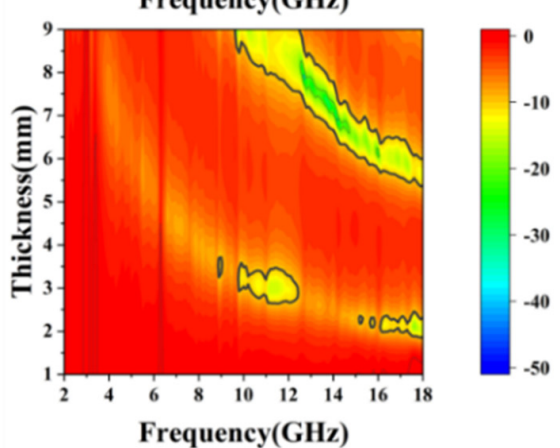

Figure 7. Three-dimensional diagrams and contour diagrams of the RL values of $(\mathbf{a}, \mathbf{b}) \mathrm{Co}_{3} \mathrm{O}_{4},(\mathbf{c}, \mathbf{d}) \mathrm{S} 1$, (e,f) S2 and (g,h) S3. 


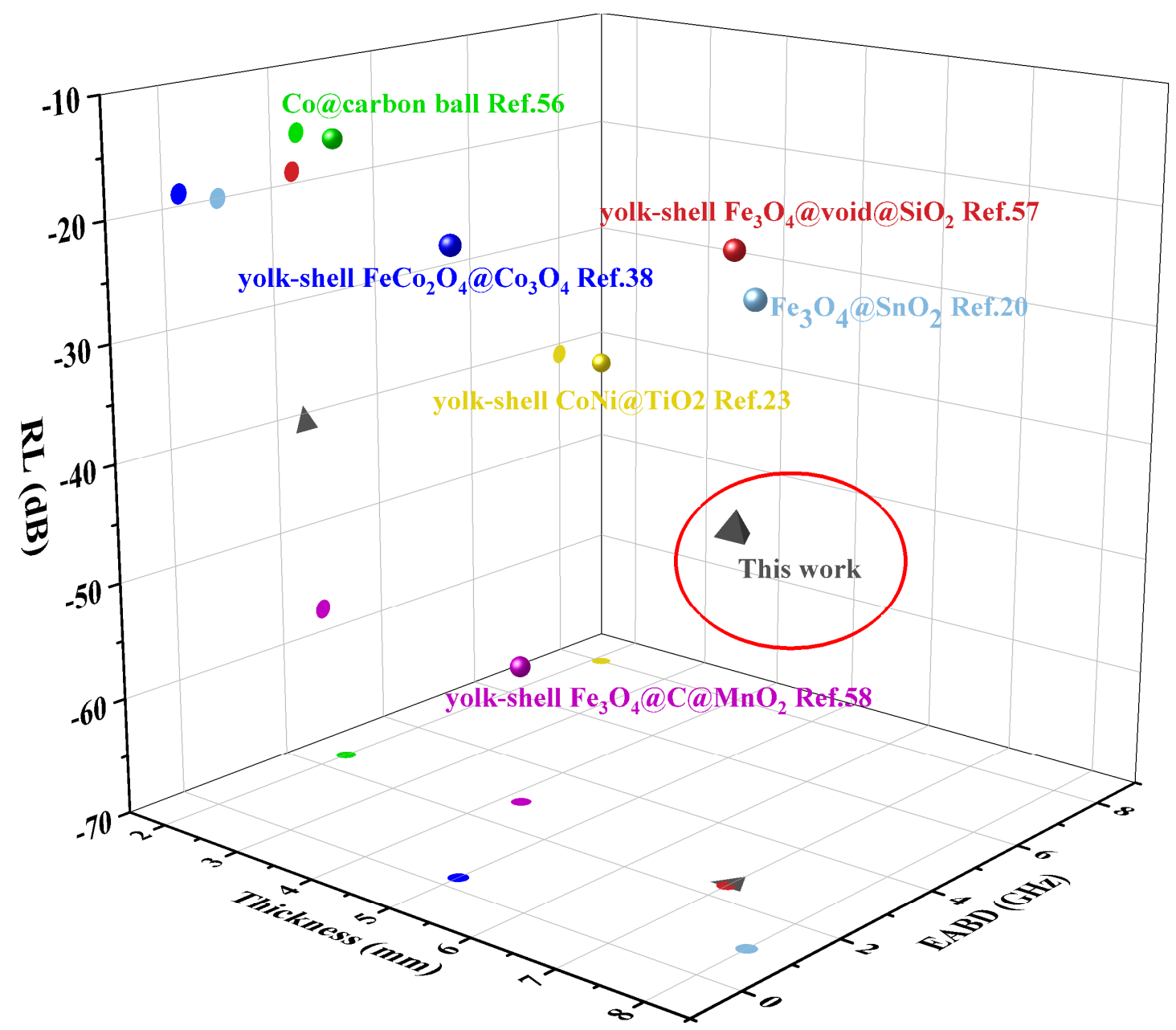

Figure 8. Microwave absorption performance of yolk-shell Co@C composites compared with that of other reported yolk-shell composites.

The microwave absorption performance can be due to the unique yolk-shell structure and the composite loss mechanism of metal cobalt and carbon shell. The microwave absorption mechanism of Co@C nanospheres is shown in Figure 9. First of all, the void space of the multi-core yolk-shell Co@C nanospheres could cause multiple reflection and scattering of electromagnetic wave, resulting in the absorption and exhaustion of incident microwave. Second, as shown in Figure 9b, there are abundant interfaces between multiple metal cobalt cores and carbon layers. Due to the difference in electrical conductivity, a large number of positive and negative charges will be accumulated at these interfaces. In the high-frequency electromagnetic environment, the accumulated charges at these interfaces will generate strong polarization and promote the attenuation of electromagnetic wave. Third, a large number of dipoles caused by defects in the amorphous carbon layer will produce strong relaxation polarization under the action of high frequency external electromagnetic field, which enhances the dielectric loss ability of the composite absorption material. Fourth, with the increase in reduction temperature, the degree of graphitization of the carbon layer increases, and a large number of electrons in the carbon layer can generate micro-current under the action of the external electromagnetic field, which is conducive to enhancing the loss of conductance and converting electromagnetic energy into heat energy. Lastly, natural resonance and eddy current loss will be caused by magnetic metal cobalt under the action of electromagnetic wave in the $\mathrm{GHz}$ band, so the electromagnetic wave can be reduced by magnetic loss. These mechanisms above work together to provide excellent microwave absorption performance of Co@C nanospheres. 
(a)

(c)
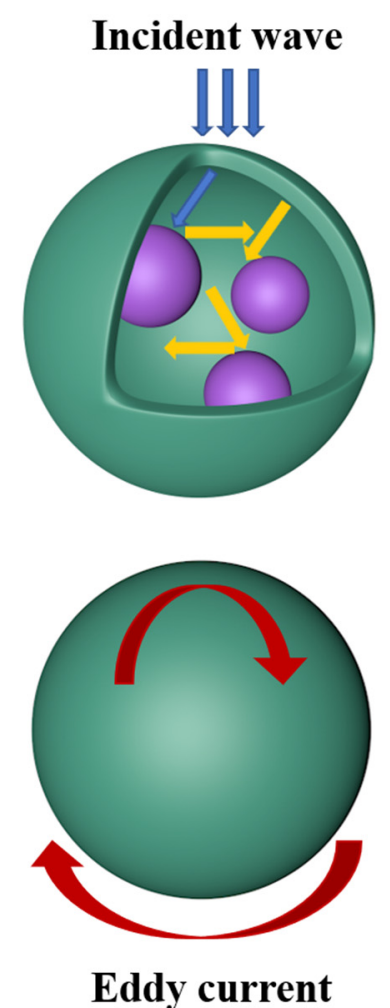

(b)

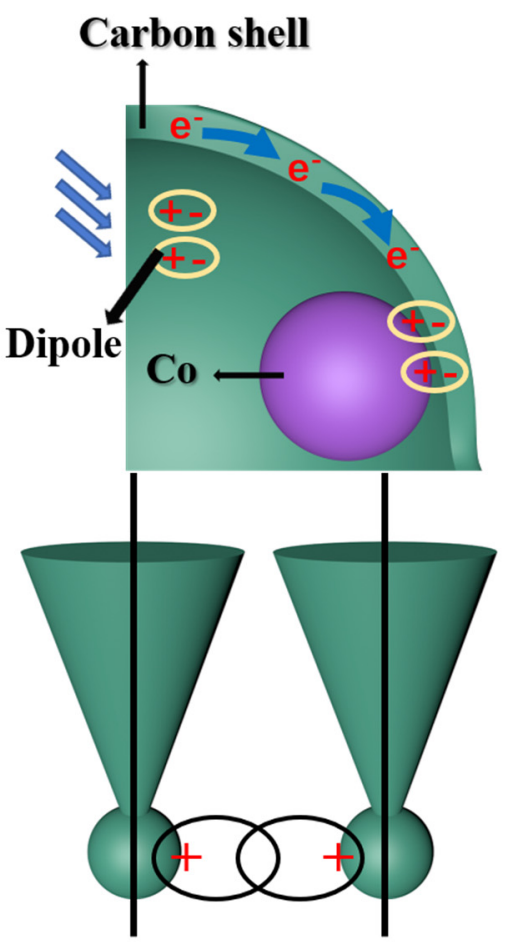

Natural resonance

Figure 9. Schematic illustration of EM wave absorption mechanisms for Co@C nanospheres: (a) multiple reflection; (b) dielectric loss mechanisms; (c) eddy current; (d) natural resonance.

\section{Conclusions}

In summary, in this study, hollow Co@C yolk-shell nanospheres with multiple metal cores were prepared by in situ reduction of $\mathrm{Co}_{3} \mathrm{O}_{4}$ in the carbon shell. This special structural design can not only reflect and scatter electromagnetic waves multiple times to achieve the purpose of the electromagnetic wave energy dissipation, but also can combine the dielectric loss and magnetic loss, making the composite Co@C absorption materials exhibt excellent absorption performance: the minimal RL value of samples carbonized at $750{ }^{\circ} \mathrm{C}$ reaches $-40 \mathrm{~dB}$ and the EABD reaches $9 \mathrm{GHz}$ with the thickness ranges from $2-9 \mathrm{~mm}$. This unique microstructural design scheme provides a new idea for the preparation of new MAM.

Author Contributions: Conceptualization, J.Q. and M.Z.; methodology, J.Q. and Z.X.; validation, M.Z. and X.S.; investigation, J.Q., Z.X.; writing-original draft preparation, J.Q.; writing-review and editing, M.Z.; visualization, J.Q.; supervision, X.S.; project administration, X.S.; funding acquisition, X.S. All authors have read and agreed to the published version of the manuscript.

Funding: This research was funded by National Natural Science Foundation of China (52072063), Research start-up fund of Foshan Graduate School of Northeastern University and the financial support of fundamental research funds for central universities (N180212009).

Institutional Review Board Statement: Not applicable.

Informed Consent Statement: Not applicable.

Data Availability Statement: The data presented in this study are available on request from the corresponding author. The data are not publicly available due to funder data retention policies.

Conflicts of Interest: The authors declare no conflict of interest.

\section{References}

1. Kong, L.B.; Li, Z.W.; Liu, L.; Huang, R.; Abshinova, M.; Yang, Z.H.; Tang, C.B.; Tan, P.K.; Deng, C.R.; Matitsine, S. Recent progress in some composite materials and structures for specific electromagnetic applications. Int. Mater. Rev. 2013, 58, 203-259. [CrossRef] 
2. Landy, N.I.; Sajuyigbe, S.; Mock, J.J.; Smith, D.R.; Padilla, W.J. Perfect metamaterial absorber. Phys. Rev. Lett. 2008, 100, 207402. [CrossRef]

3. Watts, C.M.; Liu, X.; Padilla, W.J. Metamaterial electromagnetic wave absorbers. Adv. Mater. 2012, 24, OP98-OP120. [CrossRef]

4. Imani, M.F.; Smith, D.R.; del Hougne, P. Perfect Absorption in a Disordered Medium with Programmable Meta-Atom Inclusions. Adv. Funct. Mater. 2020, 30, 2005310. [CrossRef]

5. Dong, X.L.; Zhang, X.F.; Huang, H.; Zuo, F. Enhanced microwave absorption in Ni/polyaniline nanocomposites by dual dielectric relaxations. Appl. Phys. Lett. 2008, 92, 013127. [CrossRef]

6. Huang, M.Q.; Wang, L.; Pei, K.; You, W.B.; Yu, X.F.; Wu, Z.C.; Che, R.C. Multidimension-Controllable Synthesis of MOF-Derived Co@N-Doped Carbon Composite with Magnetic-Dielectric Synergy toward Strong Microwave Absorption. Small 2020, 16, 2000158. [CrossRef] [PubMed]

7. Ge, J.W.; Liu, S.M.; Liu, L.; Cui, Y.; Meng, F.D.; Li, Y.X.; Zhang, X.F.; Wang, F.H. Optimizing the electromagnetic wave absorption performance of designed hollow $\mathrm{CoFe}_{2} \mathrm{O}_{4} / \mathrm{CoFe@C} \mathrm{microspheres.} \mathrm{J.} \mathrm{Mater.} \mathrm{Sci.} \mathrm{Technol.} \mathrm{2021,} \mathrm{81,} \mathrm{190-202.} \mathrm{[CrossRef]}$

8. Liu, J.; Cao, M.S.; Luo, Q.; Shi, H.L.; Wang, W.Z.; Yuan, J. Electromagnetic property and tunable microwave absorption of 3D nets from nickel chains at elevated temperature. ACS Appl. Mater. Interfaces 2016, 8, 22615-22622. [CrossRef]

9. Srikar, K.; Dwarapudi, S.; Kumar, D.; Sinha, G.R.; Moon, A.P. Carbonyl iron powders as absorption material for microwave interference shielding: A review. J. Alloys Compd. 2020, 853, 157251.

10. Aslam, M.A.; Ding, W.; ur Rehman, S.; Hassan, A.; Bian, Y.C.; Liu, Q.C.; Sheng, Z.G. Low cost 3D bio-carbon foams obtained from wheat straw with broadened bandwidth electromagnetic wave absorption performance. Appl. Surf. Sci. 2021, $543,148785$. [CrossRef]

11. Houbi, A.; Aldashevich, Z.A.; Atassi, Y.; Telmanovna, Z.B.; Saule, M.; Kubanych, K. Microwave absorbing properties of ferrites and their composites: A review. J. Magn. Magn. Mater. 2021, 529, 167839. [CrossRef]

12. Bandaru, S.; Murthy, N.; Kulkarni, R.; English, N.J. Magnetic ferrite/carbonized cotton fiber composites for improving electromagnetic absorption properties at gigahertz frequencies. J. Mater. Sci. 2021, 86, 127-138.

13. Du, Y.C.; Liu, W.W.; Qiang, R.; Wang, Y.; Han, X.J.; Ma, J.; Xu, P. Shell thickness-dependent microwave absorption of core-shell $\mathrm{Fe}_{3} \mathrm{O}_{4} @ \mathrm{C}$ composites. ACS Appl. Mater. Interfaces 2014, 6, 12997-13006. [CrossRef]

14. Tian, C.H.; Du, Y.C.; Cui, C.S.; Deng, Z.L.; Xue, J.L.; Xu, P.; Qing, R.; Wang, Y.; Han, X.J. Synthesis and microwave absorption enhancement of yolk-shell $\mathrm{Fe}_{3} \mathrm{O}_{4} @ \mathrm{C}$ microspheres. J. Mater. Sci. 2017, 52, 6349-6361. [CrossRef]

15. Liu, J.W.; Cheng, J.; Che, R.C.; Xu, J.J.; Liu, M.M.; Liu, Z.W. Synthesis and microwave absorption properties of yolk-shell microspheres with magnetic iron oxide cores and hierarchical copper silicate shells. ACS Appl. Mater. Interfaces 2013, 5, 2503-2509. [CrossRef]

16. Zhang, X.F.; Guan, P.F.; Dong, X.L. Transform between the permeability and permittivity in the close-packed Ni nanoparticles. Appl. Phys. Lett. 2010, 97, 033107. [CrossRef]

17. Bhattacharjee, Y.; Bose, S. Core-Shell Nanomaterials for Microwave Absorption and Electromagnetic Interference Shielding: A Review. ACS Appl. Nano Mater. 2021, 4, 949-972. [CrossRef]

18. Qiao, M.T.; Lei, X.F.; Ma, Y.; Tian, L.D.; He, X.W.; Su, K.H.; Zhang, Q.Y. Application of yolk-shell Fe $\mathrm{O}_{4} @ \mathrm{~N}$-doped carbon nanochains as highly effective microwave-absorption material. Nano Res. 2018, 11, 1500-1519. [CrossRef]

19. Moon, G.D. Yolk-shell nanostructures: Syntheses and applications for lithium-ion battery anodes. Nanomaterials 2020, 10, 675 [CrossRef]

20. Deng, Z.H.; He, S.R.; Wang, W.; Xu, M.Z.; Zheng, H.Y.; Yan, J.F.; Zhang, W.X.; Yun, J.N.; Zhao, W.; Gan, P.Y. Construction of hierarchical $\mathrm{SnO}_{2} @ \mathrm{Fe}_{3} \mathrm{O}_{4}$ nanostructures for efficient microwave absorption. J. Magn. Magn. Mater. 2020, 498, 166224. [CrossRef]

21. Chen, X.L.; Jia, Z.; Feng, A.L.; Wang, B.B.; Tong, X.H.; Zhang, C.H.; Wu, G.L. Hierarchical Fe ${ }_{3} \mathrm{O}_{4} @$ carbon@ @MnO$_{2}$ hybrid for electromagnetic wave absorber. J. Colloid Interface Sci. 2019, 553, 465-474. [CrossRef] [PubMed]

22. Gao, S.T.; Zhang, Y.C.; Xing, H.L.; Li, H.X. Controlled reduction synthesis of yolk-shell magnetic@void@C for electromagnetic wave absorption. Chem. Eng. J. 2020, 387, 124149. [CrossRef]

23. Liu, Q.H.; Cao, Q.; Bi, H.; Liang, C.Y.; Yuan, K.P.; She, W.; Yang, Y.J.; Che, R.C. CoNi@SiO $\mathrm{OTiO}_{2}$ and $\mathrm{CoNi}_{\mathrm{N}} \mathrm{Air} @ \mathrm{TiO} 2$ microspheres with strong wideband microwave absorption. Adv. Mater. 2016, 28, 486-490. [CrossRef]

24. Wang, L.; Yu, X.F.; Li, X.; Zhang, J.; Wang, M.; Che, R.C. MOF-derived yolk-shell Ni@C@ZnO Schottky contact structure for enhanced microwave absorption. Chem. Eng. J. 2020, 383, 123099. [CrossRef]

25. Chen, Y.; Chen, H.R.; Guo, L.M.; He, Q.J.; Chen, F.; Zhou, J.; Feng, J.W.; Shi, J.L. Hollow / rattle-type mesoporous nanostructures by a structural difference-based selective etching strategy. ACS Nano 2010, 4, 529-539. [CrossRef] [PubMed]

26. Zheng, N.C.; Ouyang, T.; Chen, Y.; Wang, Z.; Che, D.Y.; Liu, Z.Q. Ultrathin CdS shell-sensitized hollow S-doped CeO 2 spheres for efficient visible-light photocatalysis. Catal. Sci. Technol. 2019, 9, 1357-1364. [CrossRef]

27. Hong, Y.Y.; Pu, C.L.; Zhao, H.L.; Sheng, Q.Y.; Zhan, Q.L.; Lan, M.B. Yolk-shell magnetic mesoporous TiO ${ }_{2}$ microspheres with flowerlike $\mathrm{NiO}$ nanosheets for highly selective enrichment of phosphopeptides. Nanoscale 2017, 9, 16764-16772. [CrossRef]

28. Liu, J.W.; You, W.B.; Yu, J.Y.; Liu, X.G.; Zhang, X.F.; Guo, J.J.; Che, R.C. Electron holography of yolk-shell $\mathrm{Fe}_{3} \mathrm{O}_{4} @ \mathrm{mSiO}_{2}$ microspheres for use in microwave absorption. ACS Appl. Nano Mater. 2019, 2, 910-916. [CrossRef]

29. Qi, J.; Zhao, K.; Li, G.D.; Gao, Y.; Zhao, H.J.; Yu, R.B.; Tang, Z.Y. Multi-shelled $\mathrm{CeO}_{2}$ hollow microspheres as superior photocatalysts for water oxidation. Nanoscale 2014, 6, 4072-4077. [CrossRef] 
30. Shen, L.F.; Yu, L.; Yu, X.Y.; Zhang, X.G.; Lou, X.W. Self-templated formation of uniform $\mathrm{NiCo}_{2} \mathrm{O}_{4}$ hollow spheres with complex interior structures for lithium-ion batteries and supercapacitors. Angew. Chem. Int. Ed. 2015, 54, 1868-1872. [CrossRef]

31. Shi, L.; He, Y.R.; Hu, Y.W.; Wang, X.Z.; Jiang, B.C.; Huang, Y.M. Synthesis of size-controlled hollow $\mathrm{Fe}_{3} \mathrm{O}_{4}$ nanospheres and their growth mechanism. Particuology 2020, 49, 16-23. [CrossRef]

32. Liu, P.B.; Gao, S.; Zhang, G.Z.; Huang, Y.; You, W.B.; Che, R.C. Hollow Engineering to Co@N-Doped Carbon Nanocages via Synergistic Protecting-Etching Strategy for Ultrahigh Microwave Absorption. Adv. Funct. Mater. 2021, 2102812. [CrossRef]

33. Li, Z.N.; Han, X.J.; Ma, Y.; Liu, D.W.; Wang, Y.H.; Xu, P.; Li, C.L.; Du, Y.C. MOFs-derived hollow Co/C microspheres with enhanced microwave absorption performance. ACS Sustain. Chem. Eng. 2018, 6, 8904-8913. [CrossRef]

34. Chen, G.Z.; Xu, C.X.; Song, X.Y.; Zhao, W.; Ding, Y.; Sun, S.X. Interface reaction route to two different kinds of $\mathrm{CeO}_{2}$ nanotubes. Inorg. Chem. 2008, 47, 723-728. [CrossRef]

35. Chen, G.Z.; Sun, S.X.; Sun, X.; Fan, W.L.; You, T. Formation of $\mathrm{CeO}_{2}$ nanotubes from $\mathrm{Ce}(\mathrm{OH}) \mathrm{CO}_{3}$ nanorods through kirkendall diffusion. Inorg. Chem. 2009, 48, 1334-1338. [CrossRef]

36. Yue, Q.; Li, J.L.; Zhang, Y.; Cheng, X.W.; Chen, X.; Pan, P.P.; Su, J.C.; Elezatahry, A.A.; Alghamdi, A.; Deng, Y.H.; et al. Plasmolysisinspired nanoengineering of functional yolk-shell microspheres with magnetic core and mesoporous silica shell. J. Am. Chem. Soc. 2017, 139, 15486-15493. [CrossRef]

37. Xu, P.F.; Yu, R.B.; Ren, H.; Zong, L.B.; Chen, J.; Xing, X.R. Hierarchical nanoscale multi-shell Au/CeO 2 hollow spheres. Chem. Sci. 2014, 5, 4221-4226. [CrossRef]

38. Qin, M.; Zhang, L.M.; Zhao, X.R.; Wu, H.J. Defect Induced Polarization Loss in Multi-Shelled Spinel Hollow Spheres for Electromagnetic Wave Absorption Application. Adv. Sci. 2021, 8, 2004640. [CrossRef]

39. Zhao, B.; Guo, X.Q.; Zhao, W.Y.; Deng, J.S.; Fan, B.B.; Shao, G.; Bai, Z.Y.; Zhang, R. Facile synthesis of yolk-shell Ni@void@SnO 2 $\left(\mathrm{Ni}_{3} \mathrm{Sn}_{2}\right)$ ternary composites via galvanic replacement/Kirkendall effect and their enhanced microwave absorption properties. Nano Res. 2017, 10, 331-343. [CrossRef]

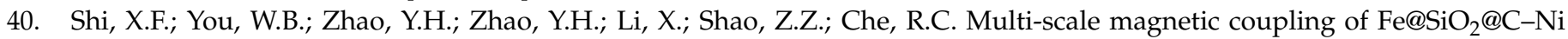
yolk@triple-shell microspheres for broadband microwave absorption. Nanoscale 2019, 11, 17270-17276. [CrossRef]

41. Wei, Y.Z.; Yang, N.L.; Huang, K.K.; Wan, J.W.; You, F.F.; Yu, R.B.; Feng, S.H.; Wang, D. Steering hollow multishelled structures in photocatalysis: Optimizing surface and mass transport. Adv. Mater. 2020, 32, 2002556. [CrossRef] [PubMed]

42. Qi, J.; Lai, X.Y.; Wang, J.Y.; Tang, H.J.; Ren, H.; Yang, Y.; Jin, Q.; Zhang, L.J.; Yu, R.B.; Ma, G.H.; et al. Multi-shelled hollow micro-/nanostructures. Chem. Soc. Rev. 2015, 44, 6749-6773. [CrossRef] [PubMed]

43. Zhao, Y.; Jiang, L. Hollow micro/nanomaterials with multilevel interior structures. Adv. Mater. 2009, 21, 3621-3638. [CrossRef]

44. Ding, D.; Wang, Y.; Li, X.D.; Qiang, R.; Xu, P.; Chu, W.L.; Han, X.J.; Du, Y.C. Rational design of core-shell Co@C microspheres for high-performance microwave absorption. Carbon 2017, 111, 722-732. [CrossRef]

45. Qiao, Z.A.; Guo, B.K.; Binder, A.J.; Chen, J.H.; Veith, G.M.; Dai, S. Controlled synthesis of mesoporous carbon nanostructures via a "silica-assisted" strategy. Nano Lett. 2013, 13, 207-212. [CrossRef]

46. Meng, X.; Liu, Y.Q.; Han, G.H.; Yang, W.W.; Yu, Y.S. Three-dimensional ( $\left.\mathrm{Fe}_{3} \mathrm{O}_{4} / \mathrm{ZnO}\right) @ C$ Double-core@shell porous nanocomposites with enhanced broadband microwave absorption. Carbon 2020, 162, 356-364. [CrossRef]

47. Teng, Z.; Zeng, S.F.; Feng, W.L.; Zhu, L.N.; Tan, Y.Q.; Han, X.C.; Chen, C.; Zhang, H.B. Facile synthesis and enhanced microwave absorption properties of Fe-Fe ${ }_{3}$ CC composites. J. Mater. Sci. Mater. Electron. 2019, 30, 14573-14579. [CrossRef]

48. Lv, H.L.; Ji, G.B.; Liu, W.; Zhang, H.Q.; Du, Y.W. Achieving hierarchical hollow carbon@ $@ \mathrm{Fe}_{\mathrm{O}} \mathrm{Fe}_{3} \mathrm{O}_{4}$ nanospheres with superior microwave absorption properties and lightweight features. J. Mater. Chem. C 2015, 3, 10232-10241. [CrossRef]

49. Liu, D.W.; Qiang, R.; Du, Y.C.; Tian, C.H.; Han, X.J. Prussian blue analogues derived magnetic FeCo alloy/carbon composites with tunable chemical composition and enhanced microwave absorption. J. Colloid Interface Sci. 2018, 514, 10-20. [CrossRef]

50. Zhou, C.H.; Wu, C.; Yan, M. Hierarchical FeCo@MoS 2 nanoflowers with strong electromagnetic wave absorption and broad bandwidth. ACS Appl. Nano Mater. 2018, 1, 5179-5187. [CrossRef]

51. Wang, C.X.; Wang, B.B.; Cao, X.; Zhao, J.W.; Chen, L.; Shan, L.G.; Wang, H.N.; Wu, G.G. 3D flower-like Co-based oxide composites with excellent wideband electromagnetic microwave absorption. Compos. B Eng. 2021, 205, 108529. [CrossRef]

52. Meng, F.B.; Wang, H.G.; Huang, F.; Guo, Y.F.; Wang, Z.Y.; Hui, D.; Zhou, Z.W. Graphene-based microwave absorbing composites: A review and prospective. Compos. B Eng. 2018, 137, 260-277. [CrossRef]

53. Jia, Z.R.; Lan, D.; Lin, K.J.; Qin, M.; Kou, K.C.; Wu, G.L.; Wu, H.J. Progress in low-frequency microwave absorbing materials. J. Mater. Sci. Mater. Electron. 2018, 29, 17122-17136. [CrossRef]

54. Shi, X.F.; You, W.B.; Li, X.; Wang, L.; Shao, Z.Z.; Che, R.C. In-situ regrowth constructed magnetic coupling 1D/2D Fe assembly as broadband and high-efficient microwave absorber. Chem. Eng. J. 2021, 415, 128951. [CrossRef]

55. Wang, L.; Yu, X.F.; Huang, M.Q.; You, W.B.; Zeng, Q.W.; Zhang, J.; Liu, X.H.; Wang, M.; Che, R.C. Orientation growth modulated magnetic-carbon microspheres toward broadband electromagnetic wave absorption. Carbon 2021, 172, 516-528. [CrossRef]

56. Li, G.M.; Wang, L.C.; Li, W.X.; Yao, X. Fe-, Co-, and Ni-Loaded Porous Activated Carbon Balls as Lightweight Microwave Absorbents. ChemPhysChem 2015, 16, 3458-3467. [CrossRef]

57. Qiao, M.T.; Wei, D.; He, X.W.; Lei, X.F.; Wei, J.; Zhang, Q.Y. Novel yolk-shell $\mathrm{Fe}_{3} \mathrm{O}_{4} @ \mathrm{void}_{\mathrm{S}} \mathrm{SiO}_{2} @ \mathrm{PPy}$ nanochains toward microwave absorption application. J. Mater. Sci. 2021, 56, 1312-1327. [CrossRef] 
58. Yang, Z.H.; Li, M.; Yang, L.J.; Liu, J.C.; Wang, Y.H.; He, Q.J. Constructing uniform $\mathrm{Fe}_{3} \mathrm{O}_{4} @ \mathrm{C} @ \mathrm{MnO}_{2}$ microspheres with yolk-shell interior toward enhancement in microwave absorption. J. Alloys Compd. 2020, 817, 152795. [CrossRef]

59. Ibrahim, I.R.; Matori, K.A.; Ismail, I.; Awang, Z.; Rusly, S.N.A.; Nazlan, R.; Idris, F.M.; Zulkimi, M.M.M.; Abdullah, N.H.; Mustaffa, M.S.; et al. A study on microwave absorption properties of carbon black and $\mathrm{Ni}_{0.6} \mathrm{Zn}_{0.4} \mathrm{Fe}_{2} \mathrm{O}_{4}$ nanocomposites by tuning the matching-absorbing layer structures. Sci. Rep. 2020, 10, 3135. [CrossRef] 